\title{
Renderização de Cenas Complexas por lluminação Global
}

\section{João Vítor B. Silva*, Hélio Pedrini}

\section{Resumo}

A renderização da iluminação de cenas complexas mostra-se um tópico de estudo importante nas áreas de computação gráfica, animação e desenvolvimento de jogos. Neste contexto, destaca-se a renderização de iluminação global em cenas complexas, tarefa primordial para se atingir os níveis de realismo desejados. Este projeto de pesquisa investiga metodologias já conhecidas da literatura e propõe um novo método, com base nos resultados encontrados.

\section{Palavras-chave:}

Iluminação Global, Renderização, Computação Gráfica.

\section{Introdução}

As áreas de computação gráfica, animação e desenvolvimento de jogos eletrônicos têm investigado ativamente nos últimos anos a aplicação de técnicas de iluminação global em cenas complexas, em destaque pelo alto nível de realismo proporcionado.

O objetivo deste projeto de pesquisa consiste em desenvolver um novo método para renderizar a iluminação de cenas complexas com maior nível de realismo, utilizando combinações de métodos e técnicas distintas já conhecidas da literatura como base.

\section{Resultados e Discussão}

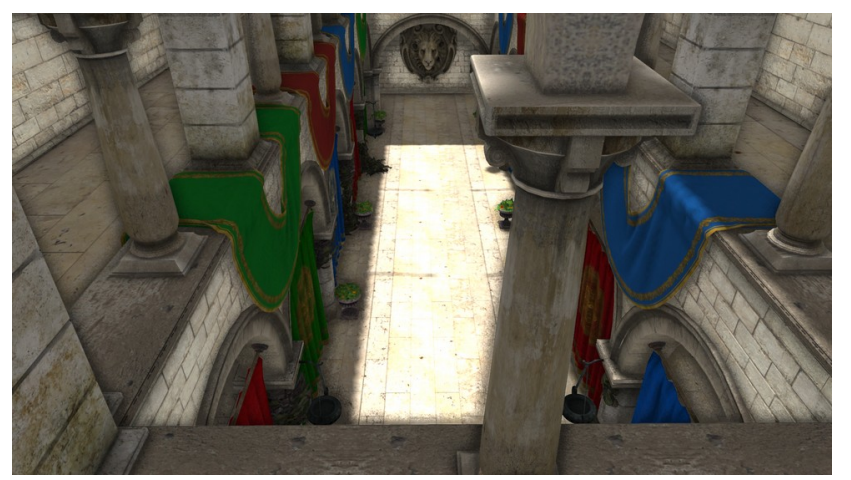

Figura 1. Cena 'Sponza Atrium', do Computer Graphics Archive', renderizada com SSAA, PCSS e SAO.

lluminação Global é o nome dado a uma série de técnicas adotadas em computação gráfica que têm por objetivo dar mais realismo às cenas, levando em conta que a luz não é apenas recebida em um ponto de forma direta, mas também refletida, proporcionando um efeito de fotorrealismo, por vezes em detrimento do desempenho. Por ser custoso computacionalmente, o efeito é muitas vezes aproximado. Oclusão é o nome dado a uma das famílias de técnicas empregadas na literatura, abordando o princípio que a geometria de uma cena bloqueia a luz incidente sobre um ponto. O Scalable Ambient Occlusion ${ }^{2}$ (SAO) apresenta melhorias em relação a outras abordagens do tipo, modularizando a iluminação da área em análise por meio de um buffer de profundidade. O Percentage-Closer Soft Shadows ${ }^{3}$ (PCSS) aplica um shader a cada pixel da cena, retornando um valor ponto flutuante que representa a quantidade de sombreamento do ponto, o que é usado em um método de filtragem PCF, resultando em sombras de maior qualidade. Super-Sampling Anti-Aliasing ${ }^{4}$ (SSAA) é uma técnica de redução de ruídos na cena de força-bruta, ao computar mais de uma amostra de uma mesma cena por pixel. Em seguida, o resultado das amostras é combinado por meio de algum filtro, como da média ou mediana.

Tabela 1. Comparação de taxa de quadros por segundo dos métodos de lluminação Global implementados para cenas diversas do Computer Graphics Archive ${ }^{1}$.

\begin{tabular}{|c|c|c|c|c|}
\hline Cena & SAO & SSAA & PCSS & $\begin{array}{c}\text { SSAA + } \\
\text { SAO + } \\
\text { PCSS }\end{array}$ \\
\hline Sponza & 60 & 60 & 60 & 30 \\
\hline Gallery & 57 & 57 & 59 & 24 \\
\hline Sibenik & 60 & 60 & 60 & 30 \\
\hline
\end{tabular}

\section{Conclusão}

Frente aos resultados obtidos, é possível observar que, de forma individual, as implementações existentes já demonstram resultados satisfatórios. A combinação de SAO, PCSS e SSAA obteve resultados de boa qualidade visual, em detrimento do desempenho. Outras técnicas, como Physically Based Rendering (PBR), ainda estão em processo de investigação e demonstram ser promissoras. Desenvolvimentos futuros incluem a combinação e comparação de PBR com as outras técnicas já implementadas previamente.

\section{Agradecimentos}

Agradeço ao meu orientador, prof. Dr. Hélio Pedrini, pelo apoio e suporte durante a elaboração do projeto, financiado pela agência de fomento PIBIC/CNPq.

\footnotetext{
${ }^{1}$ Morgan McGuire, Computer Graphics Archive. Acesso em Fevereiro/2018. http://casual-effects.com/data/index.html

${ }^{2}$ McGuire et al, Scalable Ambient Obscurance. Acesso em Fevereiro/2018. http://research.nvidia.com/sites/default/files/pubs/2012-06_Scalable-AmbientObscurance/McGuire12SAO.pdf

3 Randima, Fernando. Percentage-Closer Soft Shadows. Acesso em Fevereiro/2018

http://developer.download.nvidia.com/shaderlibrary/docs/shadow_PCSS.pdf ${ }^{4}$ Scott Owen, Super-Sampling, Siggraph Education Committee. Acesso em Julho/2018.

https://www.siggraph.org/education/materials/HyperGraph/aliasing/alias4.htm
} 